\title{
All-cause mortality in COVID-19 patients receiving statin therapy: analysis of veterans affairs database cohort study
}

\author{
Ali A. El-Solh ${ }^{1,2,3,4}$ (1) $\cdot$ Yolanda Lawson $^{1} \cdot$ Daniel A. El-Solh ${ }^{1}$
}

Received: 15 June 2021 / Accepted: 8 September 2021 / Published online: 12 October 2021

This is a U.S. government work and not under copyright protection in the U.S.; foreign copyright protection may apply 2021

\begin{abstract}
Statins have been advocated as a potential treatment for coronavirus disease-2019 (COVID-19) due to its pleotropic properties. The aim of the study was to elucidate the association between antecedent statin exposure and 30-day all-cause mortality, intensive care unit (ICU) admission and hypoxic respiratory failure requiring mechanical ventilation in patients diagnosed with COVID-19. Observational cohort study derived from the VA Corporate Data Warehouse of all veterans tested positive for COVID-19 between January 1st and May 31st, 2020. Antecedent use of statins was defined as a redeemed drug prescription in the 6 months prior to COVID-19 diagnosis. Propensity-matched mixed-effects logistic regression was performed, stratified by statin use. The study population comprised 14,268 patients with COVID-19 (median age 66 years (25th-75th percentile, 53-74), 90.7\% men), of whom 7,168 were receiving a prescription for statins. Patients with statin exposure had a greater prevalence of comorbidities and a higher risk of mortality (Odd ratio [OR] 1.52; 95\% confidence interval [CI] 1.37-1.68). After adjusting for covariates, statin exposure was not associated with a decreased mortality in the overall cohort by either Cox proportional hazards stratified model (HR 0.99; 95\% CI 0.88-1.12) or propensity matching (HR .86; 95\% CI 0.74-1.01). Similarly, there was no demonstrated advantage of statins in reducing the risk of ICU admission (HR 0.92; 95\% CI $0.74-1.31$ ) or hypoxic respiratory failure requiring mechanical ventilation (HR 1.02; 95\% CI 0.81-1.29). Antecedent statin exposure in patients with COVID-19 was not associated with a decreased risk of 30-day all-cause mortality or need for mechanical ventilation.
\end{abstract}

Keywords COVID-19 $\cdot$ Statins $\cdot$ Mortality $\cdot$ ICU admission $\cdot$ Respiratory failure $\cdot$ Mechanical ventilation

Ali A. El-Solh

solh@buffalo.edu

1 VA Western New York Healthcare System, 3495 Bailey Avenue, Buffalo, NY 14215, USA

2 Division of Pulmonary, Critical Care, and Sleep Medicine, Department of Medicine, School of Medicine and Biomedical Sciences and School of Public Health and Health Professions, State University of New York at Buffalo, Buffalo, USA

3 Department of Epidemiology and Environmental Health, School of Medicine and Biomedical Sciences and School of Public Health and Health Professions, State University of New York at Buffalo, Buffalo, USA

4 Department of Community and Health Behavior, School of Medicine and Biomedical Sciences and School of Public Health and Health Professions, State University of New York at Buffalo, Buffalo, USA

\section{Introduction}

The newly emerged Severe Acute Respiratory Syndrome Coronavirus-2 (SARS-CoV-2) has led to a global pandemic with a devastating toll on human lives. As of June 10th, 2021, the disease has affected more than 175 million and claimed the lives of 3,782,900 people with disproportionate number of deaths among Blacks and Latinos [1]. According to the most recent projections, coronavirus disease-2019 (COVID-19) reduced US life expectancy in 2020 by approximately 1.13 years [2]. Although the risk-adjusted mortality from the disease has dropped since March 2020, the rise of new circulating COVID-19 variants is threatening to halt the gains made by mass vaccination.

SARS-CoV-2 binds to the angiotensin-converting enzyme-2 (ACE- 2) receptors that are avidly expressed in the ciliated airway epithelial cells, type II pneumocytes, heart, kidney, and vascular endothelium [3]. Once the virion propagates into the host, it precipitates extensive tissue inflammation triggered by 
the secretion of cascade of pro-inflammatory cytokines such as IL- $1 \beta$ and IL-18 through the activation of well-conserved intracellular immune pathways such as the Toll-like receptors (TLRs), the NOD- and pyrin-domain containing protein 3 inflammasome, and indirectly by the release of damageassociated molecular patterns (DAMPS) from injured cells [4-6]. This cascade of events promotes recruitment of regulatory immune cells via the secretion of chemotactic cytokines, including CCL2, CCL3, and CCL4, and CXCL10 [7]. An exuberant inflammatory response ensues which is further complicated by down-regulation of Interferon-I and -III host response and impaired cytolytic activity of natural Killer cells [7-9]. The severity of the disease is further amplified by widespread arterial and capillary microthrombosis due to SARS-CoV2-induced endotheliopathy [10].

It has been hypothesized that statin treatment may reduce morbidity and mortality from COVID-19 [11]. Statins' mechanism of action depends on reversibly inhibiting 3-hydroxy-3-methylglutaryl coenzyme A (HMG-CoA) reductase by binding to the enzyme's active site [12]. This inhibition prevents the synthesis of important downstream isoprenoids, such as farnesyl pyrophosphate and geranylgeranyl pyrophosphate, which results ultimately in dampening the intracellular signaling pathways involved in inflammation, immunomodulation, and proliferative disorders [13]. The pleotropic effects of these agents can also improve vascular function by up-regulating the expression of nitric oxide accounting for their anti-thrombotic properties [14].

With the paucity of effective interventions during the initial phase of the pandemic and the "cytokine storm" that accompanies the most severe form of the disease [15], several studies have reported on the potential benefits of statins on mortality and reduced need for intensive care without incurring higher rate of adverse events [11, 16, 17]. However, these findings were not universal. A meta-analysis of nine studies has failed to replicate the survival advantage of statins in hospitalized patients with COVID-19 [18]. More worrisome was the increased mortality rate observed among COVID-19 patients with Type-2 diabetes taking statins [19]. In view of these conflicting results, we conducted a multicenter retrospective cohort study to analyze the effect of statins in patients with COVID-19 on 30-day all-cause mortality, need for intensive care, and hypoxic respiratory failure requiring invasive mechanical ventilation in attempts to provide clinical guidance to management of COVID-19.

\section{Methods}

The study was conducted in accordance with the accepted standard for reporting of epidemiologic studies (STROBE) using routinely collected health data (RECORD) guidelines [20].

\section{Data source}

We performed a retrospective longitudinal cohort review study using the Veterans Health Administration (VHA) Corporate Data Warehouse (CDW) through the VA Informatics and Computing Infrastructure (VINCI). Itemized entries were linked to VA electronic healthcare records and VA's death registry. Available data include demographics, comorbidity index, outpatient and inpatient encounters, diagnoses, procedures, laboratory data, treatment modalities, discharge dates, and death information. The Institutional Review Board deemed the study exempt from the Common Rule. The VA Research and Development Committee approved the study.

\section{Study population}

All patients' records above the age of 18 years who tested positive between January 1st, 2020 and May 31st, 2020 for SARS-CoV-2 reverse transcriptase-polymerase chain reaction from samples of nasopharyngeal or oropharyngeal specimens were extracted from the VA's Corporate Data Warehouse (CDW). The date at which the test was recorded as positive was referred to as the index date [21]. To be included in the analysis, veteran had to meet the definition of VHA user which requires receiving care from VHA for at least 2 years prior to entry into the cohort. We excluded cases who had less than two encounters whether inpatients or outpatients in the previous two years, had COVID test performed outside of the VA due to lack of complete information, were receiving hospice/palliative care, or were hospitalized prior to acquiring COVID-19.

\section{Exposure}

The statins prescribed were identified according to either their generic or trade name. Statin use was recorded as a binary measure and was defined as at least one prescription filled in the last 6 months. To have an accurate view of statin use, VHA data were linked to CMS drug information to identify both VA prescribed and non-VA prescribed statin users. Previous statin users were included in the non-users' cohort only if the time from the last prescription was longer than 6 months.

\section{Covariates}

Clinical and demographic covariates consisted of patients' age at diagnosis, race (white, black, other, unknown), ethnicity, body mass index (BMI) [(underweight $(<18.5 \mathrm{~kg} /$ $\mathrm{m}^{2}$ ), normal weight $\left(18.5-24.9 \mathrm{~kg} / \mathrm{m}^{2}\right)$, overweight 
$\left(25.0-29.9 \mathrm{~kg} / \mathrm{m}^{2}\right)$, obese $\left.\left(\geq 30 \mathrm{~kg} / \mathrm{m}^{2}\right)\right]$, and smoking history. Diagnoses codes as defined by the International Classification of Diseases and Related Health Problems, Tenth Revision (ICD-10) [22] were utilized to identify comorbidities in both cohorts and comprised hypertension, diabetes mellitus, chronic heart disease, chronic kidney disease, cancer, and human immunodeficiency virus infection. The burden of comorbidities was assessed according to the Charlson comorbidity index [23]. Patients were further classified based on whether their comorbidity index was $0,1-2,2-3$, or greater than or equal to 4 . Smoking status was derived from an algorithm developed and validated in VHA electronic records [24].

\section{Endpoints of the study}

The primary endpoint of our study was 30-day all-cause mortality. Secondary endpoints were ICU admission and hypoxic respiratory failure requiring invasive mechanical ventilation within 30 days of COVID-19 infection.

\section{Statistical analysis}

Patient characteristics and comorbidities were summarized as mean and standard deviation (SD) for normally distributed continuous variables or median and interquartile range (IQR) otherwise. Categorical variables were reported as frequency. The differences between the groups were determined using the two-sample Student's $t$ test or the Mann-Whitney Wilcoxon rank-sum test for continuous variables and Pearson's chi-squared test for categorical variables. The effects of statins on 30-day all-cause mortality were explored by a multivariate logistic regression model. The model was adjusted on a priori-decided baseline variables of clinical interest and on those with a $p$ value of less than 0.05 in the univariate analysis. Unadjusted and adjusted Cox regression models were used to estimate the association between statin use and study endpoints as a time to event. Multicollinearity in all multivariate models was assessed with the variation inflation factor.

A propensity score-matched (PSM) analysis calculated by logistic regression model was applied to reduce the selection bias. The incorporated variables in the logistic model included basic demographic characteristics (age and gender), BMI, smoking status, comorbidities, and prescription medications prior to index date (glucocorticoids, anticoagulants). Variables that were associated with exposure but not outcome were excluded. The balance of covariates was assessed by estimating standardized differences before and after matching with a caliper of 0.1. Kaplan-Meier curves were generated to visualize the cumulative incidence of the outcome over time among the propensity-matched cohorts and log-rank tests were used to compare the survival distribution between statin and non-statin users. Secondary outcomes were also computed using the propensity score adjustment. A Cox proportional hazards regression analysis for 30-day all-cause mortality in the propensity score-matched cohort was performed. A sensitivity analysis was conducted to adjust for potential clustering of patients within VA healthcare system facilities using a robust sandwich covariate matrix estimate. We also performed a subgroup analysis to assess the association of sex and race on overall 30-day mortality from COVID-19. Because of the higher expected mortality, a survival analysis was made on the propensitymatched cohort of hospitalized patients with respect to statin use. To reduce selection bias due to the missing data, missing values were imputed using the method of Multivariate Imputation Using Chained Equations. A two-side a less than 0.05 was considered statistically different. Statistical analyses were performed using Stata, version 15 (STATA Corp).

\section{Results}

\section{Baseline characteristics}

Among the 14,268 patients with confirmed SARS-COV-2, a total of 7,168 were receiving treatment with statins from January 1st, 2020, to May 1st, 2020. Missing values accounted for $<2 \%$ of all variables. The flow chart of the study cohort is presented in Fig. 1. No patients were lost to follow-up for the primary outcome. At the time of analysis, all patients in both groups had met the end point of death, discharge alive, or transferred to a long-term care facility. The median age was 66 years (IQR 53-74). The characteristics of the study population are shown in Table 1. Atorvastatin, rosuvastatin, and simvastatin were the most prescribed agents. Before PSM, the statin group is older in age, more likely to be male, and of white race compared to the non-statin group. The prevalence of obesity, hyperlipidemia, hypertension, chronic diseases was also higher in patients who were on statins than those who were not. The Charlson Index was also significantly worse in the statin group than its counterpart indicating a higher burden of comorbidities.

The results of the comparison of baseline characteristics between the COVID-19 group and the control group after PSM are presented in Table 1. Figure 2 shows the distribution of the propensity scores after PSM to be comparable. All ASDs between the two groups were $<0.1$, reflecting adequate balance between the 2 groups.

\section{Clinical outcomes}

The 30-day crude mortality for the total cohort was $12 \%$. There were 3093 (21.6\%) out of 14,268 who were hospitalized for worsening symptoms. The median time from testing 
Fig. 1 Flow chart of the study cohort

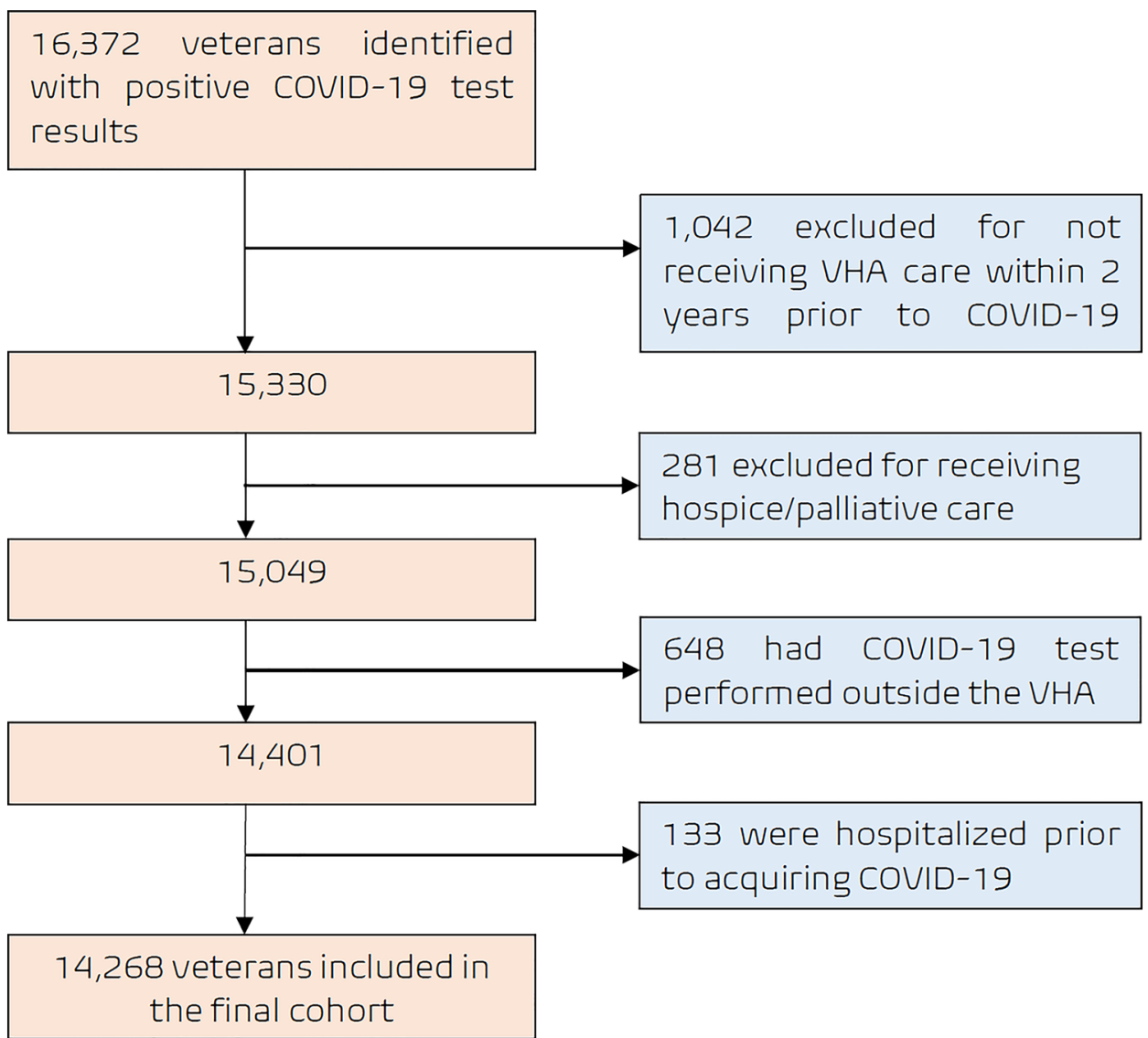

positive for COVID-19 and hospital admission was 5 days (IQR 1-8). 1660 out of 14,268 patients required intensive care unit admission. At 30 days, there were 1035 of 7168 $(14.4 \%)$ deaths in the statin group and 710 of $7100(10.0 \%)$ in non-statin group (Odds ratio [OR] 1.52, 95\% confidence interval $[\mathrm{CI}] 1.37-1.68, P<0.001)$. A total of 525 out of $6,643(7.9 \%)$ statin-treated patients died during hospitalization, compared with 288 of 6,812 (4.7\%) controls (OR 1.87; 95\% CI1.61-2.17, $P<0.001)$.

On univariate analysis, patients receiving statins showed a higher mortality than those who did not (OR 1.52; 95\% CI $1.37-1.68 ; p<0.001)$. However, statins were more likely to be prescribed in those with comorbid diseases (OR 7.49; 95\% CI 6.88-8.14; $p<0.001)$. Multivariate logistic regression analysis identified age (OR 1.08; 95\% CI 1.07-1.09; $p<0.001$ ), BMI (OR 1.01; 95\% CI 1.0-1.02; $p=0.007$ ), smoking (OR 1.14; 95\% CI 1.07-1.21; $p<0.001$ ), and Charlson comorbidity index (OR 1.17; 95\% CI 1.13-1.21; $p<0.001)$ as independent predictors of 30-day all-cause mortality but not antecedent statin (OR 0.94; 95\% CI 0.84-1.07; $p=0.4$ ), anticoagulant (OR 1.02; 95\% CI $0.91-1.17 ; p=0.72$ ), angiotensin-converting enzyme (ACE) inhibitor (OR 0.99, 95\% 0.88-1.13; $p=0.95$ ), or steroid use (OR 1.04; 95\% CI 0.76-1.43; $p=0.76$ ). The unadjusted hazard ratio for 30-day mortality in statin users was $1.54(95 \%$
CI $1.39-1.71 ; p<0.001)$. In the multivariable Cox regression model for the entire cohort, the statin group showed a comparable 30-day all-cause mortality with the non-statin group (HR, 0.99; 95\% CI, 0.88-1.12; $p=0.92$ ) (Table 2).

The risk-adjusted rates for intensive care unit admission and mechanical ventilation in patients receiving statin therapy compared to those who did not were HR $1.02(95 \%$ CI 0.84-1.18; $p=0.71$ ) and HR 1.06 (95\% CI 0.9-1.25; $p=0.47)$, respectively.

\section{Propensity score matching}

After matching by propensity score, the risk of 30-day allcause mortality was lower among statin users, but short of statistical significance (HR $0.86(0.74-1.0) ; p=0.06)$. There were no differences in the use of remdesivir or tocilizumab between the two groups ( $p=0.68$ and $p=0.83$, respectively). A Kaplan-Meier curve of survival by statin use in the propensity-matched cohort is shown in Fig. 3. PSM secondary outcomes with on time to event analysis were similar in the two cohorts regarding intensive care unit admission and hypoxic respiratory failure (Table 3 ). The time to respiratory failure requiring invasive mechanical ventilation was no different between statin and non-statin users [3 days (IQR $1-6$ ) and 3 days (IQR 0-8), respectively; $p=0.97$ ], nor was 
Table 1 Comparison of baseline characteristics of statin and non-statin users in patients with COVID-19

\begin{tabular}{|c|c|c|c|c|c|c|}
\hline & No statin $(n=7100)$ & Statin $(n=7168)$ & $p$ value & No statin $(n=2692)$ & Statin $(n=2692)$ & $p$ value \\
\hline Age (years) & $58.9 \pm 18.6$ & $68.2 \pm 11.9$ & $<0.001$ & $67.0 \pm 13.9$ & $67.1 \pm 14.2$ & 0.75 \\
\hline \multicolumn{7}{|l|}{ Age, $n(\%)$} \\
\hline$<50$ & $2328(33)$ & $425(6)$ & $<0.001$ & $400(15)$ & $389(14)$ & 0.67 \\
\hline $50-59$ & $1275(18)$ & $1096(15)$ & $<0.001$ & $490(18)$ & $517(19)$ & 0.34 \\
\hline $60-69$ & $1246(17)$ & $2005(28)$ & $<0.001$ & $599(22)$ & $641(24)$ & 0.17 \\
\hline $70-79$ & $1183(16)$ & $2462(34)$ & $<0.001$ & $698(26)$ & $697(26)$ & 0.98 \\
\hline$\geq 80$ & $1068(15)$ & $1180(16)$ & 0.02 & $505(19)$ & $448(17)$ & 0.04 \\
\hline Sex, $n(\%)$ & & & $<0.001$ & & & 0.87 \\
\hline Male & $6136(86)$ & $6808(95)$ & & $2507(93)$ & $2504(93)$ & \\
\hline Female & $963(14)$ & $360(5)$ & & $185(7)$ & $188(7)$ & \\
\hline \multicolumn{7}{|l|}{ Race, $n(\%)$} \\
\hline Caucasians & $3608(51)$ & $3577(50)$ & 0.27 & $1394(52)$ & $1343(50)$ & 0.16 \\
\hline Black & $2634(37)$ & $3096(43)$ & $<0.001$ & $1050(39)$ & $1097(41)$ & 0.19 \\
\hline Latinos & $657(9)$ & $359(5)$ & $<0.001$ & $194(7)$ & $195(7)$ & 0.96 \\
\hline Other & $201(3)$ & $136(2)$ & $<0.001$ & $54(2)$ & $57(2)$ & 0.77 \\
\hline BMI, $\left(\mathrm{kg} / \mathrm{m}^{2}\right)$ & $29.9 \pm 6.5$ & $30.2 \pm 6.7$ & 0.02 & $30.2 \pm 6.6$ & $30.1 \pm 6.8$ & 0.87 \\
\hline \multicolumn{7}{|c|}{ BMI categories, $n(\%)$} \\
\hline Underweight & $139(2)$ & $150(2)$ & 0.56 & $62(2)$ & $75(3)$ & 0.26 \\
\hline Normal & $1193(17)$ & $1196(17)$ & 0.85 & $451(17)$ & $475(18)$ & 0.39 \\
\hline Overweight & $2543(36)$ & $2301(32)$ & $<0.001$ & $838(31)$ & $774(29)$ & 0.06 \\
\hline Obese & $2783(39)$ & $3033(42)$ & $<0.001$ & $1157(43)$ & $1159(43)$ & 0.96 \\
\hline Very obese & $442(6)$ & $488(7)$ & & $184(7)$ & $209(8)$ & 0.19 \\
\hline \multicolumn{7}{|l|}{ Tobacco use, $n(\%)$} \\
\hline Never smoker & $2675(38)$ & $2507(35)$ & $<0.001$ & $1004(37)$ & $975(36)$ & 0.27 \\
\hline Former smoker & $2289(32)$ & $3450(48)$ & $<0.001$ & $1149(43)$ & $1213(45)$ & 0.08 \\
\hline Current smoker & $788(11)$ & $851(12)$ & 0.14 & $288(11)$ & $254(9)$ & 0.12 \\
\hline Unknown & $1348(19)$ & $360(5)$ & $<0.001$ & $251(9)$ & $250(9)$ & 0.96 \\
\hline \multicolumn{7}{|c|}{ Comorbidities, $n(\%)$} \\
\hline Hyperlipidemia & $1984(28)$ & $5995(83)$ & $<0.001$ & $1735(64)$ & $1728(64)$ & 0.85 \\
\hline COPD & $825(12)$ & $1843(26)$ & $<0.001$ & 477 (18) & $527(20)$ & 0.08 \\
\hline Diabetes mellitus & $1221(17)$ & $4144(58)$ & $<0.001$ & $1026(38)$ & $1034(38)$ & 0.82 \\
\hline Hypertension & $2964(42)$ & $5967(83)$ & $<0.001$ & $1902(71)$ & $1868(69)$ & 0.31 \\
\hline CHD & $945(13)$ & $2512(35)$ & $<0.001$ & $758(28)$ & $803(29)$ & 0.17 \\
\hline CKD & $648(9)$ & $1913(27)$ & $<0.001$ & 467 (17) & $508(19)$ & 0.03 \\
\hline Malignancy & $1105(16)$ & $2016(28)$ & $<0.001$ & $615(23)$ & $654(24)$ & 0.21 \\
\hline HIV infection & $86(1)$ & $122(2)$ & 0.01 & $39(1)$ & $49(2)$ & 0.28 \\
\hline CCI & $0(0-2)$ & $3(1-5)$ & $<0.001$ & $1(0-3)$ & $2(0-3)$ & 0.01 \\
\hline \multicolumn{7}{|c|}{ CCI classification, $n(\%)$} \\
\hline 0 & $3685(52)$ & $903(13)$ & $<0.001$ & $691(26)$ & $677(25)$ & 0.66 \\
\hline $1-2$ & $2189(31)$ & $2552(36)$ & $<0.001$ & $1141(42)$ & $1130(42)$ & 0.76 \\
\hline $3-4$ & $711(10)$ & $1750(24)$ & $<0.001$ & 487 (18) & $473(18)$ & 0.62 \\
\hline$\geq 5$ & $515(7)$ & $1936(27)$ & $<0.001$ & $373(14)$ & $412(15)$ & 0.13 \\
\hline \multicolumn{7}{|l|}{ Medications, $n(\%)$} \\
\hline Anticoagulants & $957(13)$ & $3087(43)$ & $<0.001$ & $661(25)$ & $688(26)$ & 0.39 \\
\hline Steroids & $178(3)$ & $250(3)$ & 0.001 & $85(3)$ & $74(3)$ & 0.38 \\
\hline ACE inhibitors & $859(12)$ & 3027 (42) & $<0.001$ & $834(31)$ & $884(33)$ & 0.14 \\
\hline
\end{tabular}

$B M I$ Body Mass Index, $C H D$ Chronic Heart disease, $C K D$ Chronic Kidney Disease, $C C I$ Charlson Comorbidity Index, $A C E$ angiotensin-converting enzyme 


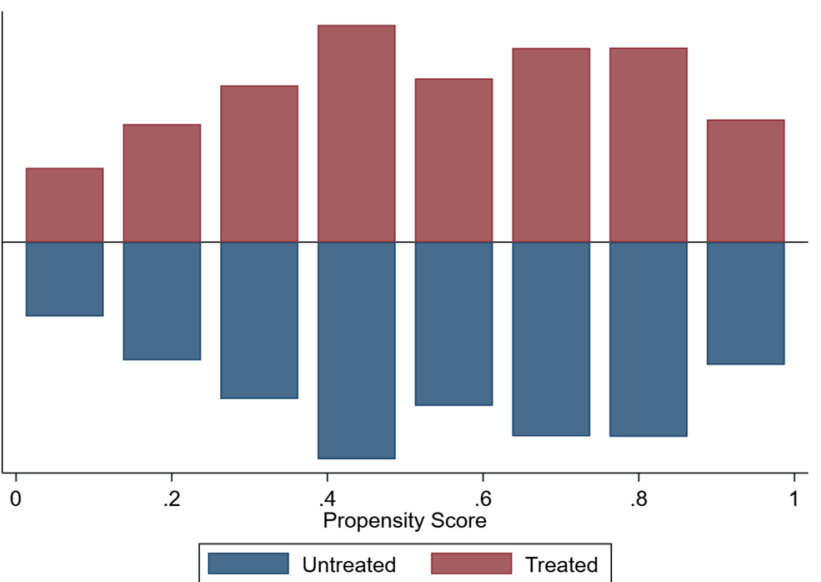

Fig. 2 Distribution of the propensity scores in the matched cohort

Table 2 Adjusted hazard ratios for 30-day all-cause mortality among the entire cohort

\begin{tabular}{lcc}
\hline & Hazard ratio $(95 \% \mathrm{CI})$ & $p$ value \\
\hline Age & $1.07(1.06-1.08)$ & $<0.001$ \\
BMI & $1.01(1.0-1.02)$ & 0.013 \\
CCI & $1.13(1.09-1.17)$ & $<0.001$ \\
smoking & $1.14(1.08-1.21)$ & $<0.001$ \\
Statin use & $0.99(0.88-1.12)$ & 0.92 \\
Anticoagulant use & $1.06(0.94-1.19)$ & 0.32 \\
Steroid use & $1.05(0.78-1.39)$ & 0.75 \\
ACE inhibitor use & $1.0(0.89-1.12)$ & 0.99 \\
\hline
\end{tabular}

$B M I$ Body Mass Index, $C C I$ Charlson Comorbidity Index, $A C E$ angiotensin-converting enzyme

the risk of respiratory failure (HR 1.02, 95\%CI 0.81-1.29; $p=0.71)$.

\section{Subgroup analysis}

In the subgroup analysis, statin use had no significant association with 30-day mortality stratified either by sex [HR $0.86 ; 95 \%$ CI $(0.75-1.0)(p=0.07)]$ or race [HR $0.89 ; 95 \%$ CI $(0.77-1.04)(p=0.144)]$. Of those hospitalized, 30-day mortality was observed in 148 (25\%) out of 586 statin users and $138(25 \%)$ out of 549 non-statin users $(p=0.96)$. Antecedent statin use did not improve in-hospital survival from COVID-19 infection (HR 1.0, 95\% CI 0.79-1.26; $p=0.99$ ).

\section{Discussion}

The results of this large multicenter retrospective study suggest that the use of statins prior to COVID-19 infection did not reduce the risk of 30-day all-cause mortality, ICU

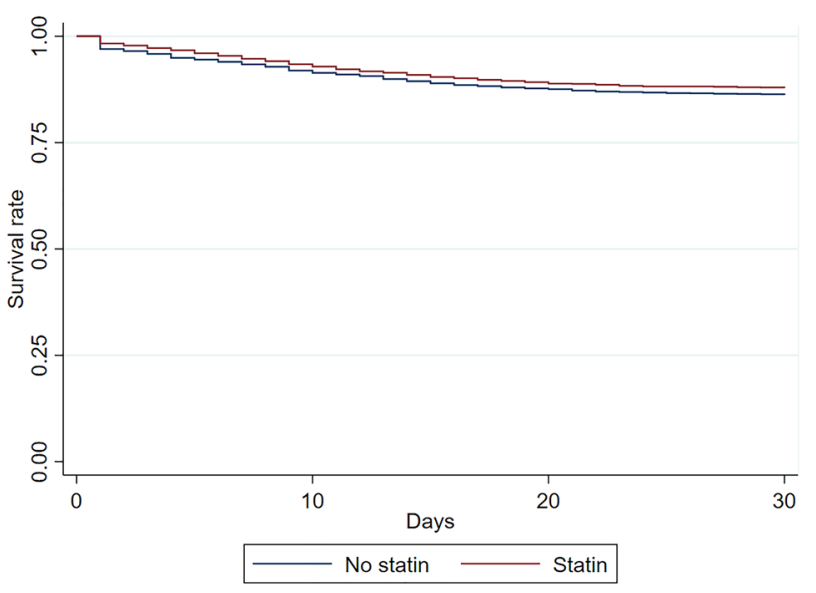

Fig. 3 Kaplan-Meier survival curve for 30-day all-cause mortality of patients with COVID-19 according to statin therapy (log rank $p=0.067$ )

admission or mechanical ventilation due to hypoxic respiratory failure.

Since the early months of the pandemic, most of the reports have highlighted the alarming fatality rate in patients with underlying comorbidities [25-27]. Older age, hypertension, cardiovascular diseases, chronic lung disease, renal failure, and obesity have all been identified as markers of worse prognosis from COVID-19 infection [19]. Given that statins are often prescribed in these conditions to mitigate the outcomes of cholesterol buildup, the crude mortality rate in our cohort was expected to be higher in statin users compared to non-statin users. A similar trend of higher mortality in statin users was observed in other studies [19, 28, 29]. Initial hypotheses have implicated the higher density of angiotensin-converting enzyme (ACE)-2 receptors-the reported mode of cell entry of COVID-19 virus-in hypertension, diabetes, and chronic obstructive pulmonary disease [30-33] promoted by statins intake [34]. However, following its insertion, SARS-CoV-2 down-regulates ACE-2 expression leaving angiotensin II to accumulate which ultimately results in end organ damage [35]. By counteracting the impact of COVID-19 on ACE- 2 expression, statins could abrogate the deleterious chain reaction of homeostatic imbalance precipitated by the intense inflammatory reaction. More recent meta-analyses have suggested that statin therapy is associated with better outcomes among patients with COVID-19, but these studies had substantial between-study heterogeneity [36, 37]. Further, retrospective studies are prone to residual bias such as the healthy user effect whereby patients taking statins are more likely to adhere to healthier lifestyles. In the current study, we have found that after adjusting for confounding elements including a propensity-matched analysis, the difference in 30-day all-cause mortality between the two groups favored the statin group although this difference 
Table 3 Association between statins and outcomes in unadjusted and adjusted analyses

\begin{tabular}{|c|c|c|c|c|c|c|}
\hline & \multicolumn{2}{|l|}{ Mortality } & \multicolumn{2}{|l|}{ ICU admission } & \multicolumn{2}{|c|}{ Mechanical ventilation } \\
\hline & $\operatorname{HR}(95 \% \mathrm{CI})$ & $p$ value & $\operatorname{HR}(95 \% \mathrm{CI})$ & $p$ value & HR $(95 \%$ CI $)$ & $p$ value \\
\hline \multicolumn{7}{|l|}{ Total cohort } \\
\hline Unadjusted & $1.54(1.39-1.71)$ & $<0.001$ & $1.07(0.91-1.24)$ & 0.41 & $1.13(0.94-1.36)$ & 0.18 \\
\hline Adjusted & $0.99(0.88-1.12)$ & 0.92 & $1.02(0.84-1.18)$ & 0.71 & $1.06(0.9-1.25)$ & 0.47 \\
\hline \multicolumn{7}{|c|}{ Propensity-matched cohort } \\
\hline PSM & $0.86(0.74-1.01)$ & 0.06 & $0.92(0.74-1.31)$ & 0.28 & $1.02(0.81-1.29)$ & 0.71 \\
\hline
\end{tabular}

Data are expressed as hazard ratio (95\% confidence interval)

PSM propensity score matching was not statistically significant. These findings are in agreement with an observation cohort study that comprised 4842 patients diagnosed with COVID-19 over the same time period of our study population [29]. The use of statins in the 6 months prior to infection with COVID-19 was not associated with an increased or decreased risk of all-cause mortality. A more recent meta-analysis identified a survival benefit from statins use in hospital but not for pre-admission use of statins [38]. Our analysis found no advantage of statins for either scenario. Interestingly, the INSPIRATION-S trial where 605 patients with COVID-19 were randomly assigned to receive atorvastatin $20 \mathrm{mg}$ daily or placebo showed that atorvastatin was not associated with a significant reduction in the primary outcome - a composite of adjudicated venous or arterial thrombosis, need for extracorporeal membrane oxygenation, or mortality within 30 days [39]. Previously, the trial of simvastatin in acute respiratory distress syndrome also showed no reduction in mortality in comparison with placebo [40].

Earlier studies have attributed the reduction in mortality from statins to the suppression of cytokine expression observed both in vivo and in vitro [41]. Levels of MCP-1, TNF- $\alpha$, IL-1, IL-6, IL-12, and metalloproteinases have been attenuated with use of atorvastatin, simvastatin, or pravastatin both in experimental and clinical investigations [42-45]. These observations have not been replicated in longitudinal studies involving patients with COVID-19. Chacko and colleagues [46] did not find any difference in the levels of inflammatory markers among statin and non-statin users at the time of hospitalization. Similarly, we were not able to discern a significant difference in the levels of IL-6 and C-reactive protein between the two groups on admission (data not shown). Based on the published studies [47], we cannot exclude the possibility of a protective role for statins in alleviating the burden of COVID-19 complications, but the mortality benefit-if established in future randomized clinical trials - may not be directly mediated by circulating inflammatory markers.

The major strength of this study is the systematic analysis of a large, multicenter electronic records of patients receiving statin therapy prior to COVID-19 infection, a consolidated methodology, and a validated statistical analysis. Our study has also limitations. First, retrospective analyses are subject to biases and incomplete data. Although our records documented filled prescriptions with the last 6 months antecedent to the COVID-19 diagnosis, data on adherence were lacking. Second, despite the relevant number of factors included in the propensity score, some factors that could impact mortality, ICU admission, and mechanical ventilation may have been missed. Third, the design of the study was based on investigating antecedent use of statin on COVD-19 outcome. These results may not be applicable to de novo statin therapy, however based on the current body of the literature, there is no evidence from randomized controlled trials that have demonstrated survival benefit from de novo initiation of statins in SARS-CoV-2 infection [39]. Fourth, prior reports have alluded that, whilst males and females are at equivalent risk of infection with COVID-19, male sex is associated with higher rate of progression to severe disease and death [48-50]. Differences in immune responses to COVID-19 between the sexes alongside varying inflammatory statuses associated with cardiovascular comorbidities, such as obesity, hypertension, and hypercholesterolemia, offer potential explanations for the worse outcomes in men with COVID-19 [51, 52]. Although statin use had no significant association with 30-day mortality when stratified by sex, a potential survival benefit from statins cannot be ruled out given that the study cohort comprised predominantly of males. Fifth, we have not assessed the risks of outcomes according to intensity of statin therapy. However, a recent meta-analysis found that high-intensity therapy was not associated with significantly different risk of allcause mortality compared with moderate- to low-intensity statin therapy [29].

In conclusion, our study showed that statin therapy did not increase or decrease the risk of 30-day all-cause mortality, ICU admission, or respiratory failure requiring mechanical ventilation. Nonetheless, further well-designed, randomized controlled studies should evaluate the role of statins as an adjunctive therapy in combination with antiviral or anti-inflammatory agents. 
Acknowledgements The views expressed in this manuscript do not communicate an official position of the Department of veterans Affairs.

Author contributions AES conceptualized the project, revised the statistical analysis, and finalized the manuscript. YL extracted the data, conducted basic statistical analysis, and drafted the manuscript. DES conducted a literature search, summarized the data, and contributed to the discussion. All authors have read and approved the manuscript.

Funding The study was supported in part by a grant from the US Department of Veterans Affairs (AES CX 001656).

\section{Declarations}

Conflict of interest Authors declare no existing conflict of interest.

Availability of data The data are owned by the US government and stored within the VINCI framework at the US department of Veterans Affairs.

Ethics approval The study is deemed exempt by the VA Western York Institutional Review Board. The Research and Development committee approved the study.

Human and animal rights All procedures and analyses performed in this study involving human participants were in accordance with the ethical standards of the institutional and/or national research committee (Research and Development Committee) and with the 1964 Helsinki declaration and its later amendments or comparable ethical standards.

Informed consent Not applicable.

\section{References}

1. Preventiion CfDCa (2021) COVID-19 Reports 2021. https://www. cdc.gov/mmwr/index.html

2. Andrasfay T, Goldman N (2021) Reductions in 2020 US life expectancy due to COVID-19 and the disproportionate impact on the Black and Latino populations. Proc Natl Acad Sci USA. https://doi.org/10.1073/pnas.2014746118 (Epub 2021/01/16; PubMed PMID: 33446511; PubMed Central PMCID: PMCPMC7865122)

3. Pawlos A, Niedzielski M, Gorzelak-Pabis P, Broncel M, Wozniak E (2021) COVID-19: direct and indirect mechanisms of statins. Int J Mol Sci. https://doi.org/10.3390/ijms22084177 (Epub 2021/05/01; PubMed PMID: 33920709; PubMed Central PMCID: PMCPMC8073792)

4. Onofrio L, Caraglia M, Facchini G, Margherita V, Placido S, Buonerba C (2020) Toll-like receptors and COVID-19: a twofaced story with an exciting ending. Future Sci OA. 6(8):FSO605. https://doi.org/10.2144/fsoa-2020-0091 (Epub 2020/09/26; PubMed PMID: 32974046; PubMed Central PMCID: PMCPMC7434222 affiliations or financial involvement with any organization or entity with a financial interest in or financial conflict with the subject matter or materials discussed in the manuscript. This includes employment, consultancies, honoraria, stock ownership or options, expert testimony, grants or patents received or pending, or royalties. No writing assistance was utilized in the production of this manuscript)

5. Merad M, Martin JC (2020) Pathological inflammation in patients with COVID-19: a key role for monocytes and macrophages. Nature Rev Immunol. 20(6):355-362. https://doi.org/10.1038/ s41577-020-0331-4 (Epub 2020/05/08; PubMed PMID: 32376901; PubMed Central PMCID: PMCPMC7201395)

6. Torres Acosta MA, Singer BD (2020) Pathogenesis of COVID19-induced ARDS: implications for an ageing population. Eur Respir J. https://doi.org/10.1183/13993003.02049-2020 (Epub 2020/08/05; PubMed PMID: 32747391; PubMed Central PMCID: PMCPMC7397945 interest: B.D. Singer has a patent US Patent App. 15/542,380, "Compositions and Methods to Accelerate Resolution of Acute Lung Inflammation" pending)

7. Zhou Z, Ren L, Zhang L, Zhong J, Xiao Y, Jia Z et al (2020) Heightened Innate Immune Responses in the Respiratory Tract of COVID-19 Patients. Cell Host Microbe 27(6):883-90 e2. https://doi.org/10.1016/j.chom.2020.04.017 (Epub 2020/05/15; PubMed PMID: 32407669; PubMed Central PMCID: PMCPMC7196896)

8. Blanco-Melo D, Nilsson-Payant BE, Liu WC, Uhl S, Hoagland D, Moller R et al (2020) Imbalanced host response to SARSCoV-2 drives development of COVID-19. Cell 181(5):1036-45 e9. https://doi.org/10.1016/j.cell.2020.04.026 (Epub 2020/05/18; PubMed PMID: 32416070; PubMed Central PMCID: PMCPMC7227586)

9. Osman M, Faridi RM, Sligl W, Shabani-Rad MT, Dharmani-Khan P, Parker A et al (2020) Impaired natural killer cell counts and cytolytic activity in patients with severe COVID-19. Blood Adv 4(20):5035-5039. https://doi.org/10.1182/bloodadvances.20200 02650 (Epub 2020/10/20; PubMed PMID: 33075136; PubMed Central PMCID: PMCPMC7594380)

10. Iba T, Levy JH, Levi M, Thachil J (2020) Coagulopathy in COVID-19. J Thromb Haemost 18(9):2103-2109. https://doi. org/10.1111/jth.14975 (Epub 2020/06/20; PubMed PMID: 32558075; PubMed Central PMCID: PMCPMC7323352)

11. Gupta A, Madhavan MV, Poterucha TJ, DeFilippis EM, Hennessey JA, Redfors B et al (2021) Association between antecedent statin use and decreased mortality in hospitalized patients with COVID-19. Nat Commun 12(1):1325. https://doi.org/10.1038/ s41467-021-21553-1 (Epub 2021/02/28; PubMed PMID: 33637713; PubMed Central PMCID: PMCPMC7910606)

12. Moghadasian MH (1999) Clinical pharmacology of 3-hydroxy3-methylglutaryl coenzyme A reductase inhibitors. Life Sci 65(13):1329-1337. https://doi.org/10.1016/s0024-3205(99) 00199-x (Epub 1999/09/30; PubMed PMID: 10503952)

13. Wang CY, Liu PY, Liao JK (2008) Pleiotropic effects of statin therapy: molecular mechanisms and clinical results. Trends Mol Med 14(1):37-44. https://doi.org/10.1016/j.molmed.2007.11.004 (Epub 2007/12/11; PubMed PMID: 18068482; PubMed Central PMCID: PMCPMC2621332)

14. Violi F, Calvieri C, Ferro D, Pignatelli P (2013) Statins as antithrombotic drugs. Circulation 127(2):251-257. https://doi.org/ 10.1161/CIRCULATIONAHA.112.145334 (Epub 2013/01/16; PubMed PMID: 23319813)

15. Ye Q, Wang B, Mao J (2020) The pathogenesis and treatment of the 'Cytokine Storm' in COVID-19. J Infect 80(6):607-613. https://doi.org/10.1016/j.jinf.2020.03.037 (Epub 2020/04/14; PubMed PMID: 32283152; PubMed Central PMCID: PMCPMC7194613)

16. Tan WYT, Young BE, Lye DC, Chew DEK, Dalan R (2020) Statin use is associated with lower disease severity in COVID-19 infection. Sci Rep 10(1):17458. https://doi.org/10.1038/s41598020-74492-0 (Epub 2020/10/17; PubMed PMID: 33060704; PubMed Central PMCID: PMCPMC7562925)

17. Vahedian-Azimi A, Mohammadi SM, Heidari Beni F, Banach M, Guest PC, Jamialahmadi T et al (2021) Improved COVID19 ICU admission and mortality outcomes following treatment with statins: a systematic review and meta-analysis. Arch Med Sci 17(3):579-595. https://doi.org/10.5114/aoms/132950 (Epub 
2021/05/25; PubMed PMID: 34025827; PubMed Central PMCID: PMCPMC8130467)

18. Hariyanto TI, Kurniawan A (2021) Statin and outcomes of coronavirus disease 2019 (COVID-19): A systematic review, meta-analysis, and meta-regression. Nutr Metab Cardiovasc Dis. https://doi.org/10.1016/j.numecd.2021.02.020 (Epub 2021/04/12; PubMed PMID: 33838992; PubMed Central PMCID: PMCPMC7910652)

19. Cariou B, Goronflot T, Rimbert A, Boullu S, Le May C, Moulin P et al (2021) Routine use of statins and increased COVID19 related mortality in inpatients with type 2 diabetes: results from the CORONADO study. Diabetes Metab 47(2):101202. https://doi.org/10.1016/j.diabet.2020.10.001 (Epub 2020/10/23; PubMed PMID: 33091555; PubMed Central PMCID: PMCPMC7572108)

20. Cuschieri S (2019) The STROBE guidelines. Saudi J Anaesth 13(Suppl 1):S31-S34. https://doi.org/10.4103/sja.SJA_543_18 (Epub 2019/04/02; PubMed PMID: 30930717; PubMed Central PMCID: PMCPMC6398292)

21. Department of Veterans Affairs, Office of Research and Development (2020) COVID-19 Shared Data Resource (September 30, 2020). https://vhacdwdwhweb100.vha.med.va.gov/phenotype/ index.php/COVID-19:Shared_Data_Resource

22. Organization WH (1992) International Statistical Classification of Diseases, Tenth Revision (ICD-10)

23. Charlson ME, Sax FL, MacKenzie CR, Braham RL, Fields SD, Douglas RG Jr (1987) Morbidity during hospitalization: can we predict it? J Chronic Dis 40(7):705-712 (Epub 1987/01/01 PubMed PMID: 3110198)

24. Song RHY, Nguyen X, Honerlaw J, Quaden R, Gaziano M, Concato J, Cho K, Gagnon D, Million Veteran Program Data Analytics Group (2016) Development of an Electronic Health RecordBased Algorithm for Smoking Status Using the Million Veteran Program (MVP) Cohort Survey Response. Circulation 134:18809

25. Arentz M, Yim E, Klaff L, Lokhandwala S, Riedo FX, Chong $M$ et al (2020) Characteristics and outcomes of 21 Critically Ill Patients With COVID-19 in Washington State. JAMA 323(16):1612-1614. https://doi.org/10.1001/jama.2020.4326 (Epub 2020/03/20; PubMed PMID: 32191259; PubMed Central PMCID: PMCPMC7082763)

26. Zadori N, Vancsa S, Farkas N, Hegyi P, Eross B, Group KS (2020) The negative impact of comorbidities on the disease course of COVID-19. Intensive Care Med 46(9):1784-1786. https://doi.org/10.1007/s00134-020-06161-9 (Epub 2020/07/01; PubMed PMID: 32601834; PubMed Central PMCID: PMCPMC7322221)

27. Oh TK, Song IA, Song KH, Jeon YT (2021) Comparison of All-Cause Mortality Between Individuals With COVID-19 and Propensity Score-Matched Individuals Without COVID-19 in South Korea. Open Forum Infect Dis 8(4):ofab057. https://doi. org/10.1093/ofid/ofab057 (Epub 2021/05/04; PubMed PMID: 33937433; PubMed Central PMCID: PMCPMC7928610)

28. Mitacchione G, Schiavone M, Curnis A, Arca M, Antinori S, Gasperetti A et al (2021) Impact of prior statin use on clinical outcomes in COVID-19 patients: data from tertiary referral hospitals during COVID-19 pandemic in Italy. J Clin Lipidol 15(1):68-78. https://doi.org/10.1016/j.jacl.2020.12.008 (Epub 2021/01/05; PubMed PMID: 33390341; PubMed Central PMCID: PMCPMC7833194)

29. Butt JH, Gerds TA, Schou M, Kragholm K, Phelps M, HaversBorgersen E et al (2020) Association between statin use and outcomes in patients with coronavirus disease 2019 (COVID-19): a nationwide cohort study. BMJ Open 10(12):e044421. https:// doi.org/10.1136/bmjopen-2020-044421 (Epub 2020/12/06; PubMed PMID: 33277291; PubMed Central PMCID: PMCPMC7722358)
30. Wan Y, Shang J, Graham R, Baric RS, Li F (2020) Receptor recognition by the novel Coronavirus from Wuhan: an analysis based on decade-long structural studies of SARS Coronavirus. J Virol. https://doi.org/10.1128/JVI.00127-20 (Epub 2020/01/31; PubMed PMID: 31996437; PubMed Central PMCID: PMCPMC7081895)

31. Zhang H, Rostami MR, Leopold PL, Mezey JG, O'Beirne SL, Strulovici-Barel Y et al (2020) Expression of the SARS-CoV-2 ACE2 receptor in the human airway epithelium. Am J Respir Crit Care Med 202(2):219-229. https://doi.org/10.1164/rccm.2020030541OC (Epub 2020/05/21; PubMed PMID: 32432483; PubMed Central PMCID: PMCPMC7365377)

32. Puelles VG, Lutgehetmann M, Lindenmeyer MT, Sperhake JP, Wong MN, Allweiss L et al (2020) Multiorgan and Renal Tropism of SARS-CoV-2. N Engl J Med 383(6):590-592. https://doi.org/ 10.1056/NEJMc2011400 (Epub 2020/05/14; PubMed PMID: 32402155; PubMed Central PMCID: PMCPMC7240771)

33. Hikmet F, Mear L, Edvinsson A, Micke P, Uhlen M, Lindskog C (2020) The protein expression profile of ACE2 in human tissues. Mol Syst Biol 16(7):e9610. https://doi.org/10.15252/msb.20209 610 (Epub 2020/07/28; PubMed PMID: 32715618; PubMed Central PMCID: PMCPMC7383091)

34. Castiglione V, Chiriaco M, Emdin M, Taddei S, Vergaro G (2020) Statin therapy in COVID-19 infection. Eur Heart J Cardiovasc Pharmacother. 6(4):258-259. https://doi.org/10.1093/ehjcvp/ pvaa042 (Epub 2020/04/30; PubMed PMID: 32347925; PubMed Central PMCID: PMCPMC7197622)

35. Madjid M, Safavi-Naeini P, Solomon SD, Vardeny O (2020) Potential effects of coronaviruses on the cardiovascular system: a review. JAMA Cardiol. 5(7):831-840. https://doi.org/10.1001/ jamacardio.2020.1286 (Epub 2020/03/29; PubMed PMID: 32219363)

36. Pal R, Banerjee M, Yadav U, Bhattacharjee S (2021) Statin use and clinical outcomes in patients with COVID-19: An updated systematic review and meta-analysis. Postgrad Med J. https:// doi.org/10.1136/postgradmedj-2020-139172 (Epub 2021/02/06; PubMed PMID: 33541927; PubMed Central PMCID: PMCPMC7868124)

37. Wu CC, Lee AJ, Su CH, Huang CY, Islam MM, Weng YC (2021) Statin Use Is associated with a decreased risk of mortality among patients with COVID-19. J Clin Med. https://doi.org/10.3390/ jcm10071450 (Epub 2021/05/01; PubMed PMID: 33916281; PubMed Central PMCID: PMCPMC8036545)

38. Permana H, Huang I, Purwiga A, Kusumawardhani NY, Sihite TA, Martanto E et al (2021) In-hospital use of statins is associated with a reduced risk of mortality in coronavirus-2019 (COVID-19): systematic review and meta-analysis. Pharmacol Rep 73(3):769-780. https://doi.org/10.1007/s43440-021-00233-3 (Epub 2021/02/21; PubMed PMID: 33608850; PubMed Central PMCID: PMCPMC7895740)

39. Bikdeli B, Talasaz AH, Rashidi F, Sharif-Kashani B, Farrokhpour M, Bakhshandeh $\mathrm{H}$ et al (2020) Intermediate versus standard-dose prophylactic anticoagulation and statin therapy versus placebo in critically-ill patients with COVID-19: Rationale and design of the INSPIRATION/INSPIRATION-S studies. Thromb Res 196:382-394. https://doi.org/10.1016/j.thromres.2020.09.027 (Epub 2020/09/30; PubMed PMID: 32992075; PubMed Central PMCID: PMCPMC7513771)

40. McAuley DF, Laffey JG, O'Kane CM, Perkins GD, Mullan B, Trinder TJ et al (2014) Simvastatin in the acute respiratory distress syndrome. N Engl J Med 371(18):1695-1703. https://doi.org/10. 1056/NEJMoa1403285 (Epub 2014/10/01; PubMed PMID: 25268516)

41. Kashour T, Halwani R, Arabi YM, Sohail MR, O'Horo JC, Badley AD et al (2021) Statins as an adjunctive therapy for COVID19: the biological and clinical plausibility. Immunopharmacol 
Immunotoxicol 43(1):37-50. https://doi.org/10.1080/08923973. 2020.1863984 (Epub 2021/01/08; PubMed PMID: 33406943)

42. Zelvyte I, Dominaitiene R, Crisby M, Janciauskiene S (2002) Modulation of inflammatory mediators and PPARgamma and NFkappaB expression by pravastatin in response to lipoproteins in human monocytes in vitro. Pharmacol Res 45(2):147-154. https:// doi.org/10.1006/phrs.2001.0922 (Epub 2002/02/16; PubMed PMID: 11846628)

43. Niessner A, Steiner S, Speidl WS, Pleiner J, Seidinger D, Maurer G et al (2006) Simvastatin suppresses endotoxin-induced upregulation of toll-like receptors 4 and 2 in vivo. Atherosclerosis 189(2):408-413. https://doi.org/10.1016/j.atherosclerosis.2005. 12.022 (Epub 2006/01/31; PubMed PMID: 16443229)

44. Ascer E, Bertolami MC, Venturinelli ML, Buccheri V, Souza J, Nicolau JC et al (2004) Atorvastatin reduces proinflammatory markers in hypercholesterolemic patients. Atherosclerosis 177(1):161-166. https://doi.org/10.1016/j.atherosclerosis.2004. 07.003 (Epub 2004/10/19; PubMed PMID: 15488879)

45. Moutzouri E, Tellis CC, Rousouli K, Liberopoulos EN, Milionis HJ, Elisaf MS et al (2012) Effect of simvastatin or its combination with ezetimibe on Toll-like receptor expression and lipopolysaccharide - induced cytokine production in monocytes of hypercholesterolemic patients. Atherosclerosis 225(2):381-387. https:// doi.org/10.1016/j.atherosclerosis.2012.08.037 (Epub 2012/10/16; PubMed PMID: 23062767)

46. Chacko SR, DeJoy R 3rd, Lo KB, Albano J, Peterson E, Bhargav R et al (2021) Association of Pre-admission statin use with reduced in-hospital mortality in COVID-19. Am J Med Sci. https://doi.org/10.1016/j.amjms.2021.03.001 (Epub 2021/03/06; PubMed PMID: 33667433; PubMed Central PMCID: PMCPMC7923853)

47. Zhang XJ, Qin JJ, Cheng X, Shen L, Zhao YC, Yuan Y et al (2020) In-Hospital Use of Statins Is Associated with a Reduced Risk of Mortality among Individuals with COVID-19. Cell Metab 32(2):176-874. https://doi.org/10.1016/j.cmet.2020.06.015 (Epub 2020/06/28; PubMed PMID: 32592657; PubMed Central PMCID: PMCPMC7311917)
48. Peckham H, de Gruijter NM, Raine C, Radziszewska A, Ciurtin C, Wedderburn LR et al (2020) Male sex identified by global COVID-19 meta-analysis as a risk factor for death and ITU admission. Nat Commun 11(1):6317. https://doi.org/10.1038/s41467020-19741-6 (Epub 2020/12/11; PubMed PMID: 33298944; PubMed Central PMCID: PMCPMC7726563)

49. Ramirez-Soto MC, Arroyo-Hernandez H, Ortega-Caceres G (2021) Sex differences in the incidence, mortality, and fatality of COVID-19 in Peru. PLoS ONE 16(6):e0253193. https:// doi.org/10.1371/journal.pone.0253193 (Epub 2021/06/15; PubMed PMID: 34125851; PubMed Central PMCID: PMCPMC8202928)

50. Gebhard C, Regitz-Zagrosek V, Neuhauser HK, Morgan R, Klein SL (2020) Impact of sex and gender on COVID-19 outcomes in Europe. Biol Sex Differ 11(1):29. https://doi.org/10.1186/s13293020-00304-9 (Epub 2020/05/27; PubMed PMID: 32450906; PubMed Central PMCID: PMCPMC7247289.)

51. Jin JM, Bai P, He W, Wu F, Liu XF, Han DM et al (2020) Gender Differences in Patients With COVID-19: Focus on Severity and Mortality. Front Public Health 8:152. https://doi.org/10. 3389/fpubh.2020.00152 (Epub 2020/05/16; PubMed PMID: 32411652; PubMed Central PMCID: PMCPMC7201103)

52. Lu R, Zhao X, Li J, Niu P, Yang B, Wu H et al (2020) Genomic characterisation and epidemiology of 2019 novel coronavirus: implications for virus origins and receptor binding. Lancet 395(10224):565-574. https://doi.org/10.1016/S0140-6736(20) 30251-8 (Epub 2020/02/03; PubMed PMID: 32007145; PubMed Central PMCID: PMCPMC7159086)

Publisher's Note Springer Nature remains neutral with regard to jurisdictional claims in published maps and institutional affiliations. 